\title{
Effectiveness and Mechanism of Preoperative Lugol Solution for Reducing Thyroid Blood Flow in Patients with Euthyroid Graves' Disease: Reply
}

\author{
Shih-Ming Huang ${ }^{1}$
}

Published online: 17 May 2016

(c) Société Internationale de Chirurgie 2016

To the Editor,

Thank you very much for your important queries. In this series, $31 \%$ of the patients had ophthalmopathy. The doses of antithyroid drugs were varied substantially: methimazole from 15 to $60 \mathrm{mg} /$ day and propylthiouracil from 150 to $300 \mathrm{mg} / \mathrm{day}$, and the mean weight of the thyroid gland was $53 \mathrm{~g}$ (range 35-202). Neither the dose of the antithyroid drugs nor the weight of the thyroid gland affected the reduction of vascularity in this study. Blood flow was the main factor affecting blood loss: if the patients had the same blood flow on the operative day, blood loss did not show any significant difference between the patients with lugol solution and those without lugol solution. From our experience, blood loss seems to be controllable in the experienced hand for the thyroid with blood flow less than four times normal, and those patients might not need lugol solution. Mild stomach irritation is the most common drawback of using lugol solution, but diluting it and drinking it with juice or eating it with food (e.g., milk) can easily overcome this problem. If a patient misses a scheduled operation, to avoid escape phenomena after taking high-dose iodine, an antithyroid drug should be continuously used until the thyroidectomy can be performed.
Shih-Ming Huang

smhuang@mail.ncku.edu.tw

1 National Cheng-Kung University, Tainan, Taiwan 